\title{
Patterns of adverse childhood experiences and depressive symptoms: self-esteem as a mediating mechanism
}

\author{
Youngmi Kim ${ }^{1} \cdot$ Haenim Lee ${ }^{2} \cdot$ Aely Park $^{3}$
}

Received: 30 January 2021 / Accepted: 22 June 2021 / Published online: 30 June 2021

○) Springer-Verlag GmbH Germany, part of Springer Nature 2021

\begin{abstract}
Purpose There is a growing interest in the co-occurring natures of adverse childhood experiences (ACEs) and unmeasured types of adversity. The current body of knowledge may also lack plausible mechanisms linking ACEs to mental health in young adulthood. This study aims to identify early adversity patterns using expanded ACEs items and investigate the pathway of ACEs and self-esteem to depressive symptoms in young adulthood.

Methods Data were obtained from the National Longitudinal Study of Adolescent and Adult Health, including a nationally representative sample in the U.S. $(N=10,702)$. We identified the ACEs patterns and estimated the direct and indirect associations between ACEs and depressive symptoms through self-esteem, using a latent class analysis with a distal outcome.

Results This study identified four distinct groups of ACEs that include Child Maltreatment, Household Dysfunction, Violence, and Low Adversity. The Child Maltreatment class showed a significantly higher risk of depressive symptoms compared to other ACEs groups. Self-esteem mediated the negative association of child maltreatment with depressive symptoms. The Violence class presented a significantly higher risk of depressive symptoms than Low Adversity, but no mediation of selfesteem was found.

Conclusion The study highlights the profound consequence of child abuse/neglect and identifies self-esteem as a plausible mediating mechanism. Researchers and practitioners should increase collaboration efforts to prevent early adversity exposures and detrimental effects on mental health.
\end{abstract}

Keywords Adverse childhood experiences · Self-esteem · Depressive symptoms · National Longitudinal Study of Adolescent Health · Latent class analysis

\section{Introduction}

\section{Adverse childhood experiences (ACEs)}

Aely Park

apark@scnu.ac.kr

Youngmi Kim

ykim@vcu.edu

Haenim Lee

hnl22@dgu.ac.kr

1 School of Social Work, Virginia Commonwealth University, 1000 Floyd Avenue, PO Box 842027, Richmond, VA 23220, USA

2 Department of Social Welfare and Counselling, Dongguk University, 30 Pildong-ro 1gil, Jung-gu, Seoul, South Korea 04629

3 Department of Social Welfare, Sunchon National University, 255 Jungang-ro, Suncheon, Jeonnam, South Korea 57922
Adverse childhood experiences (ACEs) are stressful or harmful life events, including emotional, physical, and sexual abuse and neglect, and growing up in a household with problems of violence, mental illness, incarceration, and substance misuse [1, 2]. Exposures to ACEs are prevalent. Earlier statistics from the Kaiser-CDC ACE study reported that more than $50 \%$ of respondents experienced at least one ACE [3, 4] and recent studies document similar levels of prevalence [5]. Research shows that ACEs do not occur in isolation. Different types of adversity experiences are interrelated, and the majority of those with any exposure had multiple forms of ACEs [6, 7]. Numerous research has presented significant relationships between ACEs and social (e.g., school outcomes, self-esteem, and homelessness), 
behavioral (e.g., heavy alcohol or drug use; violence perpetration and victimization, and suicidal behavior), and health outcomes (e.g., obesity, diabetes, cardiovascular disease, cancer, depression, and anxiety) [8,9]. Early adversities show a graded relationship to these outcomes, that is, the effect intensifies as the cumulative number of experiences increases $[2,10]$.

Recent studies argue that the current scientific literature may be limited with respect to how unmeasured ACEs may impact social behavioral and health outcomes [11, 12]. Most prior studies of ACEs focus on experiences in home environments [2, 3, 13, 14], and many of previous studies were conducted with White, middle-class, and average or higher educated samples $[4,10,15,16]$. Minority populations or socioeconomically disadvantaged groups might be more exposed to-and consequently impacted by - other types of childhood adversities, such as community violence [17-19]. Cronholm and his colleagues [15] examined expanded ACEs that included community-level adversity experiences. Their study found that approximately $14 \%$ of respondents reported only expanded ACEs, such as witnessed violence, discrimination, unsafe neighborhood, experienced bullying, and lived in foster care, while almost half of their study sample reported both conventional and expanded ACEs. Also, associated socioeconomic characteristics differed between the conventional and expanded ACEs; for example, the expanded ACEs were more observed in males, racial and ethnic minorities, and low-income groups. In addition, the study by Wade and his colleagues [19] showed that conventional ACEs and expanded ACEs appeared to lead to somewhat different risks of physical health. The number of both conventional and expanded ACEs increased the risk of mental illness and depressive symptoms, while only conventional ACEs were associated with physical health problems.

\section{ACEs and depressive symptoms}

Depressive symptoms are one of the most concerning mental health outcomes of ACEs [20-23]. Several studies have demonstrated that the risk of depression/depressive symptoms increased as the number of adversities incremented [24]. Using the Kaiser-CDC ACE data, Felitti and his colleagues [4] presented that the odds of having a depressed mood/feeling was more than three times higher for adults with four or more ACEs than those without any past adversity [25]. One study utilized a sample from Saudi Arabia and presented consistent results that those with four or more ACEs had almost five times higher odds of depression compared to the no adversity group [26]. A study conducted with responses from female Hawaii residents in the Behavioral Risk Factor Surveillance System Survey also found the positive association and the increasing odds of depressive symptoms with the cumulative count of ACEs [27].

\section{Self-esteem as a mediating mechanism}

We focus on the role of self-esteem as a plausible mechanism in which ACEs influence depressive symptoms. Adolescents develop their own coping system in response to stress from the influences of parents and family environments [28]. Severe and cumulative adversity exposure can trigger the development of a poor self-concept and, consequently, depression [29], whereas secure attachment in childhood is critical in fostering a positive self-value [30]. Children and adolescents with adverse experiences are less likely to receive parental care and support, which increases the risk of developing a distorted self-concept and feeling less worthy/important, that is, low self-esteem or negative self-evaluation and withdrawal from socialization [31].

Prior research supports the theoretical link of ACEs and self-esteem effects on mental health [32-34]. Children and adolescents with a history of abuse or neglect exhibit higher levels of negative self-evaluation than their counterparts [35, 36]. Shen [37] suggests that self-esteem is significantly lower for those experiencing both physical maltreatment and family violence compared to those experiencing either or none. Children experiencing maltreatment have a higher likelihood of having depressive symptoms and mental health issues through low levels of self-esteem [38, 39].

\section{Current study}

Despite the well-documented evidence of ACEs and depression/depressive symptoms and the role of selfesteem in mental health, there is a dearth of evidence on the pathway from ACEs patterns, self-esteem, to depression/depressive symptoms. This study aimed to unpack the underlying mechanisms between the expanded ACEs and depressive symptoms through self-esteem. We noted that prior research suggested co-occurring patterns of ACEs and the dose-response relationship between ACEs and mental health. While the majority of studies relied on cumulative scores and/or dichotomized indicators of each adversity type, emerging research sheds light on ACEs profiles in explaining associated outcomes [14, 40-42]. For instance, the analysis by Merians and her colleagues [13] identified four distinct groups of ACEs that included high ACEs, non-violent household dysfunctions, child abuse, and low ACEs. They found significant differences in mental health between the ACES groups, while it was largest between high ACEs and low ACEs.

Guided by prior research, this study has two main objectives: (1) to identify ACEs patterns using the expanded scope of childhood adversities and (2) to investigate the 
pathway from the ACEs patterns, self-esteem, and depressive symptoms in young adulthood. Our specific hypotheses for the second objective include the following: (a) ACE classes differ in self-esteem, (b) ACE classes differ in depressive symptoms, (c) self-esteem is associated with depressive symptoms, and (d) self-esteem mediates the association between ACEs and depressive symptoms.

\section{Method}

\section{Data and sample}

Data were obtained from the National Longitudinal Study of Adolescent and Adult Health (Add Health): Wave I (1994-1995), Wave III (2001-2002), and Wave IV (2008-2009). The Add Health began in 1994 with a nationally representative sample of students in grades 7-12 drawn from 80 high schools and 52 middle schools in the United States. The participants were recruited using stratified, multistage, and school-based cluster sampling methods $(N=20,745)$ to generate representative estimates in terms of regions, urbanity, school size and type, and ethnicity [43, 44]. The study oversampled groups of ethnic minorities (Chinese, Cuban, and Puerto Rican adolescents), Black adolescents with highly educated parent(s), siblings, adoptees, and adolescents with disabilities. Of 10,784 adolescents who participated in all three waves and whose main caregivers completed the Wave I parent survey, we excluded 82 adolescents with missing data in the covariates (less than $1 \%$ of the sample). The final analysis sample consisted of 10,702 adolescents.

\section{Measures}

The dependent variable was depressive symptoms. The 10-item Center for Epidemiologic Studies-Depression Scale (CES-D) was used to measure depressive symptoms in young adulthood (Wave IV). The scale measured feelings and behaviors regarding somatic symptoms and depressed affect in the past week using 10 items 4-point Likert scale $(0=$ "rarely or never" to $3=$ "most or all"). After aggregating the 10 items (Cronbach alpha $=0.84$ ), we created a dichotomous variable that coded 1 for those with significant depressive symptoms (scores at 10 or higher) and 0 otherwise, following previous studies [45].

The independent variable was ACEs. To identify the classes of ACEs, we used 12 indicators of early adversities that included (1) physical neglect, (2) emotional neglect, (3) physical abuse, (4) emotional abuse, (5) sexual abuse, (6) suicidal attempt of household adult, (7) parental alcohol misuse, (8) parental separation or divorce, (9) incarceration of household adult, (10) poverty, (11) violence witnessing, and (12) violence victimization. Data came from adolescent's retrospective reports about their experiences before age 18 (neglect, abuse, violence, suicide, and incarceration of household adult members; collected in Wave I, III, or IV) and the parent's Wave I survey (parental divorce/separation, alcohol misuse, and public assistance). We created 12 dichotomous variables, guided by previous studies [46-48].

The following questions were used for physical abuse, emotional abuse, and sexual abuse, respectively: before your 18th birthday, how often had one of your parents or other adult caregivers "hit you with a fist, kick you, or throw you down on the floor, into a wall, or downstairs?", "say things that really hurt your feelings or made you feel like you were not wanted or loved?", and "touch you in a sexual way, force you to touch him or her in a sexual way, or force you to have sexual relations?"; for physical neglect, "By the time you started $6^{\text {th }}$ grade, how often had your parents or other adult caregivers left you home alone when an adult should have been with you?"). We coded as 1 if the respondent indicated any experience of each $(1=$ one-time to $5=$ more than ten times) and 0 otherwise (never happened). Emotional neglect was assessed with two questions: "Most of the time, your [father] or [mother] is warming and loving toward you." Emotional neglect was identified $(=1)$ if the respondent disagreed or strongly disagreed with either of the two questions, 0 otherwise. Parental incarceration was measured using four questions: "(Has/did) your [biological mother, biological father, mother figure, or father figure] ever (spent/ spend) time in jail or prison?" ( $1=$ any of them, $0=$ none). A suicidal attempt of a household adult was measured with "Have any of your family members tried to kill themselves during the past 12 months?" $(1=$ yes, $0=$ no). Parental alcohol misuse was affirmed if either of the biological mother or father reports alcoholism problems $(=1)$. Parental separation or divorce was coded 0 if the respondent had married parents and 1 otherwise. Poverty was coded as 1 if the respondent received any of the following in the past month and 0 otherwise: (a) Supplemental Security Income (SSI), (b) Aid to Families with Dependent Children (AFDC), (c) food stamps, and (4) a housing subsidy or public housing". Violence witnessing was measured by a question "During the past 12 months, how often did you see someone shoot or stab another person" $(1=$ one or more than once, $0=$ none $)$. Violence victimization was identified if the respondent indicated any experience in the following questions ( 1 for any; 0 for never happened): "During the past 12 months, how often did the following happen? (a) someone pulled a knife or gun on you; (b) someone shot or stabbed you; (c) someone cut or stabbed you"; (d) you were jumped.

The mediating variable was self-esteem that measured global feelings of self-worth. Four questions adapted from Rosenberg's short-form scale were collected in Wave III: (1) having a lot of good qualities; (2) having a lot to be proud 
of; (3) like yourself just the way you are; (4) feeling you are doing things just about right. Response options ranged from strongly agree $(=1)$ to strongly disagree $(=5)$. We reversecoded and created a total score indicating that higher scores mean higher levels of self-esteem (Cronbach alpha $=0.78$ ).

This study included covariates to control for demographic and socioeconomic characteristics that were known to have associations with self-esteem or depressive symptoms in prior studies [49-53]: age, gender, race and ethnicity, education, marital status, public assistance, and depressive symptoms in adolescence. Gender indicated male $(=0)$ or female $(=1)$. Race and ethnicity included the following five groups: non-Hispanic White (reference group), nonHispanic Black, non-Hispanic Asian, non-Hispanic others, and Hispanics. Educational attainment was categorized into three groups of less than high school, high school diploma or GED, and college or higher (reference group). Marital status was dummy-coded: married or lived with a partner $(=1), 0$ otherwise. Public assistance was an indicator for whether the respondent ever received public assistance such as food stamps, AFDC/TANF, or housing assistance between Wave I and Wave III. The presence of depressive symptoms status in adolescence was included to control for earlier mental health status and confounding factors. The information of age, gender, race, and adolescence depressive symptoms came from Wave I, and the other covariates from Wave III in young adulthood.

\section{Statistical analysis}

First, we described the demographic and socioeconomic characteristics of our sample. Second, we performed a Latent Class Analysis (LCA) to identify the ACEs classes using 12 indicators. This analytic method identifies unobservable classes of a latent variable of interest, based on the patterns of responses among observed variables [54]. To select the number of classes and the best-fitting model, we assessed the model fits with the Akaike information criterion (AIC), the Bayesian information criterion (BIC), the adjusted BIC, Entropy, and the Lo-Mendell-Rubin Likelihood Ratio test (LMRT) [55]. For classification, we used average posterior probabilities greater than 0.70 and conditional item probabilities $[54,56]$. In addition to statistical evaluation criteria, we also used the existing literature for substantively meaningful identification of classes.

Third, we tested the direct and indirect associations of the classified ACEs on depressive symptoms through selfesteem in young adulthood, controlling for socioeconomic status and early depressive symptoms. We used the Bolck, Croons, and Hagenaars (BCH) method [57-59]. All analyses were performed using sampling weights to account for the complex survey design and non-response bias. The findings presented population-based estimates generalizable to the U.S. population. We employed Mplus version 8.1.

\section{Results}

\section{Sample characteristics}

Table 1 summarized socioeconomic characteristics and early depressive symptoms in the full sample. The sample included a balanced gender composition with an average age of 15 at Wave I. The majority was White $(68 \%)$, completed high school $(73 \%)$, or neither married nor cohabitated $(68 \%)$ at Wave III. In young adulthood, the proportion of those who received public assistance was $7 \%$, and the average score of self-esteem was $17(S D=2.3)$. Those at risk for clinically significant depressive symptoms consisted of $14 \%$ in adolescence, the proportion increased to $30 \%$ in young adulthood.

\section{Patterns of ACEs}

Table 2 shows the model fit statistics for 2 through 5-class LCA models of ACEs. While the AIC and BIC were the smallest in the 5 class model, the four-class model showed statistically significant LMR $(p<0.001)$, Entropy also suggested that the 4-class model had adequate precision of

Table 1 Sample characteristics (weighted)

\begin{tabular}{ll}
\hline & Mean / \% (SD) \\
\hline Age (Mean, SD) & $15.28(1.8)$ \\
Gender (\%) & \\
Male & 49.08 \\
Female & 50.92 \\
Racelethnicity (\%) & \\
White & 68.2 \\
Hispanic & 11.1 \\
Black & 14.6 \\
Asian & 3.1 \\
Others & 3.0 \\
Education (\%) & \\
Less than high school & 10.4 \\
High school graduate & 73.0 \\
College or higher & 16.6 \\
Marital status (\%) & \\
Married/cohabitating & 31.8 \\
Unmarried & 68.2 \\
Public assistance (\%) & 6.6 \\
Self-esteem (Mean, SD) & $16.9(2.3)$ \\
Depression- adolescence (\%) & 13.9 \\
Depression- adulthood (\%) & 30.3 \\
\hline
\end{tabular}

Notes. Unweighted $N=10,702$ 
Table 2 Model selection criteria for the classification of adverse childhood experiences

\begin{tabular}{llllll}
\hline Model & AIC & BIC & Adjusted BIC & Entropy & $\begin{array}{l}\text { Lo-mendell-rubin } \\
\text { adjusted LRT } \\
\text { p-value }\end{array}$ \\
\hline 2-Class & $104,726.38$ & $104,908.53$ & $104,829.08$ & 0.59 & $<.001$ \\
3-Class & $103,452.27$ & $103,729.13$ & $103,608.37$ & 0.67 & $<.001$ \\
4-Class & $\mathbf{1 0 2 , 8 1 5 . 6 0}$ & $\mathbf{1 0 3 , 1 8 7 . 1 7}$ & $\mathbf{1 0 3 , 0 2 5 . 1 0}$ & $\mathbf{0 . 7 3}$ & $<.001$ \\
5-Class & $102,393.66$ & $102,859.96$ & $102,656.57$ & 0.70 & .1665 \\
\hline
\end{tabular}

Note. Final solutions are in bold; AIC akaike information criterion, BIC bayesian information criterion, LMRT Lo-mendell-rubin likelihood ratio test classification. In addition to model fit criteria, the 4-class model was well-aligned with substantive interpretability. Thus, we selected the 4-class solution as the optimal model for ACE patterns.

Figure 1 displays the patterns of the four classes of ACEs along with item response probabilities (Y-axis): Child Maltreatment, Household Dysfunction, Violence, and Low Adversity. The majority was classified as Low Adversity (61\%). The Child Maltreatment and Household Dysfunction consisted of $17 \%$, respectively, and the Violence was about 5\%. The Child Maltreatment class was estimated to have high probabilities of experiencing physical neglect $(61 \%)$, physical abuse (67\%), and emotional abuse $(100 \%)$ in their childhood. The Household Dysfunction class was estimated to have high exposures to parental alcohol misuse (49\%), parental separation or divorce $(72 \%)$, parental incarceration (41\%), and poverty (47\%). The Violence class showed high probabilities of witnessing violence (89\%) and being a victim of violence (100\%). The Low Adversity class indicated low probabilities of slightly over $30 \%$ in physical neglect and emotional abuse and very low probabilities in most ACE items.

\section{ACEs, self-esteem, and depressive symptoms}

Table 3 presented the direct and indirect paths from the classified ACEs, self-esteem, to depressive symptoms, controlling for the covariates. The analysis used Low Adversity as a reference group. The Violence $(\mathrm{b}=0.07, p=0.03)$ and Child Maltreatment groups $(\mathrm{b}=0.18, p<0.001)$ had a significantly higher likelihood of depressive symptoms in young adulthood than the Low Adversity. Self-esteem was significantly lower for the Child Maltreatment group compared to the Low Adversity group $(b=-0.63, p<0.001)$. Self-esteem was negatively associated with depressive symptoms, indicating that those with higher self-esteem showed a significantly lower risk of clinically concerning depressive symptoms in young adulthood $(\mathrm{b}=-0.30, p<0.001)$. We found that there was a significant indirect association of self-esteem in the pathway for the Child Maltreatment group, compared to the Low Adversity group $(\mathrm{b}=0.02, p<0.001)$.

Besides, our additional analysis with different reference groups showed that the Violence and Household Dysfunction groups presented significantly lower rates of depressive symptoms $(b=-0.11, p<0.01 ; b=-0.15, p<0.001$ respectively) and higher levels of self-esteem $(b=0.59, p=0.001$; $\mathrm{b}=0.57, p=0.001$, respectively) than the Child Maltreatment group. The indirect association of self-esteem through depressive symptoms was also different for the Child Maltreatment group compared to the Violence ( $\mathrm{b}=-0.02, p=0.001)$ and Household Dysfunction groups $(b=-0.02, p=0.001)$. Figure 2 illustrates the direct and indirect associations.
Fig. 1 Patterns of ACEs (weighted)

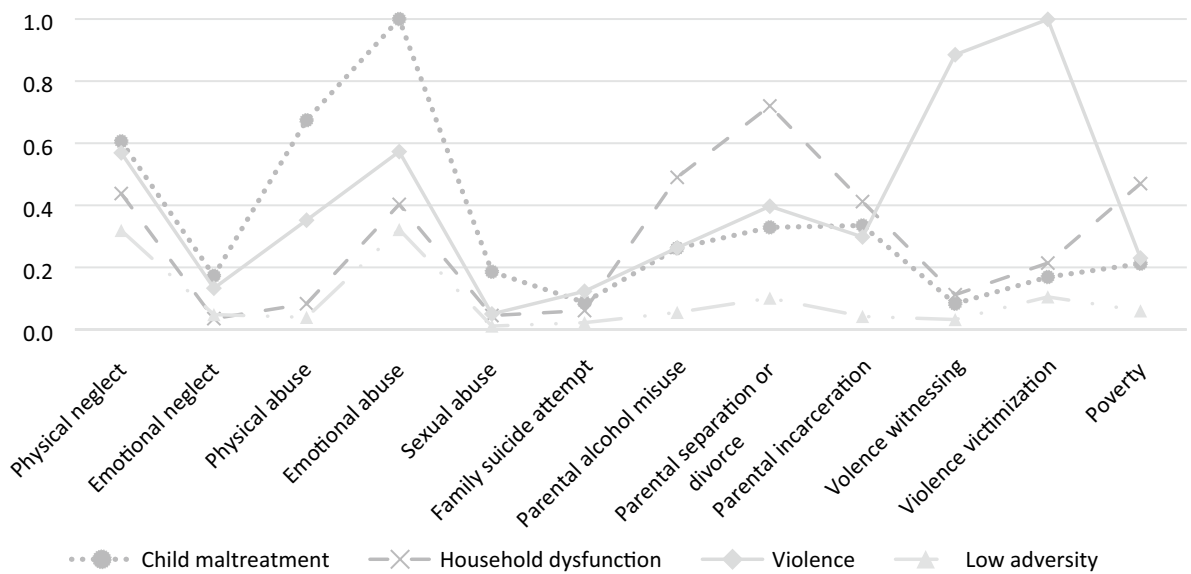


Table 3 The Direct and Indirect Associations of ACEs on Depression (weighted)

\begin{tabular}{lc}
\hline Direct effect & Standardized Estimates $(S E)$ \\
\hline Depression & $0.029(0.026)$ \\
ACEs & $0.074(0.035)^{*}$ \\
Household dysfunction & $0.181(0.022)^{* * *}$ \\
Violence & $-0.030(0.003)^{* * *}$ \\
Child maltreatment & \\
Self-esteem & $-0.036(0.150)$ \\
Self-esteem & $-0.060(0.165)$ \\
ACEs & $-0.631(0.096)^{* * *}$ \\
Household dysfunction & \\
Violence & \\
Child maltreatment & $0.001(0.005)$ \\
\hline Indirect effect & $0.002(0.005)$ \\
\hline Household dysfunction $\rightarrow$ self-esteem $\rightarrow$ depression & $0.019(0.003)^{* * *}$ \\
Violence $\rightarrow$ self-esteem $\rightarrow$ depression & depression \\
Child maltreatment $\rightarrow$ self-esteem $\rightarrow$ d & \\
\hline
\end{tabular}

Notes. $N=10,702$. The weighted analysis controls for age, gender, race/ethnicity, public assistance in adulthood, education, marital status, and depressive symptoms in adolescence. Unstandardized estimates reported with standard errors in parentheses. The reference group of ACEs is Low Adversity. ${ }^{*} p<.05,{ }^{* *} p<.01,{ }^{* * * *} p<.001$

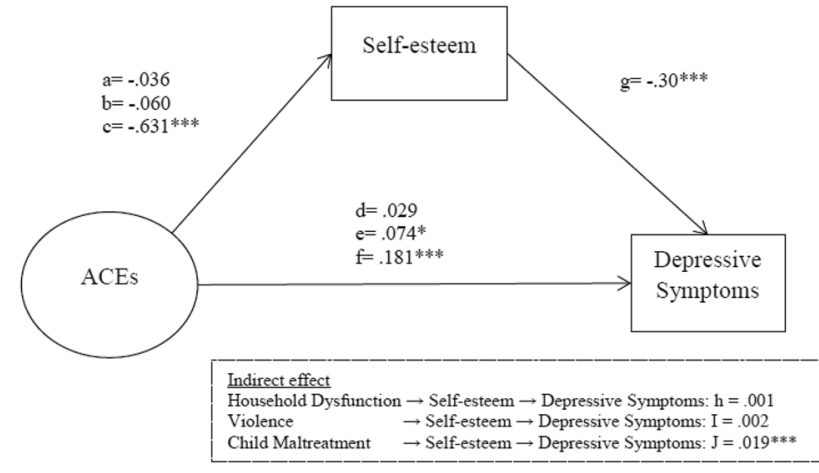

Fig. 2 Summary of path analysis results (weighted). Notes. $N=10,702 .{ }^{*} p<.05,{ }^{* * *} p<.001$. The weighted analysis controls for socioeconomic characteristics and early depressive symptoms. The reference group of ACEs is Low Adversity. Unstandardized estimates reported with standard errors in parentheses: "a" and "d" indicates the difference between Household Dysfunction and Low Adversity; "b" and "e" indicates the difference between Violence and Low Adversity; "c" and "f" indicates the difference between Child Maltreatment and Low Adversity

Of the covariates, gender, race, and education were directly associated with depressive symptoms. Depressive symptoms were more likely to be reported by females $(b=0.04, p<0.001)$ than males. Compared to Whites, racial and ethnic minorities showed a significantly higher probability of having depressive symptoms in emerging adulthood: Hispanics $(b=0.05, p<0.01)$, Blacks $(b=0.10, p<0.001)$, and Asians $(\mathrm{b}=0.07, p=0.02)$. Those who had less than a high school degree $(b=0.20, p<0.001)$ and high school degree $(b=0.07, p<0.001)$ were more likely to have depressive symptoms than those who had college or higher education attainment.

\section{Discussion}

This study promotes our knowledge of the consequences of early adversity using data from a nationally representative sample. First, the study identifies four distinct groups of ACEs that include Child Maltreatment, Household Dysfunction, Violence, and Low Adversity. Second, exposure to child maltreatment is likely to result in depressive symptoms more than other ACE groups. The study also finds that self-esteem mediates the negative association of child maltreatment with depressive symptoms.

Prior studies discuss several natures of ACEs. Those exposed to ACEs tend to experience more than one ACE; in other words, the co-occurrence and inter-correlations of individual ACEs. Multiple types of exposures worsen mental health problems. While some specific forms of ACEs may exert strong effects, individual adversities appear to bring shared and cumulative consequences rather than in isolation $[7,8]$. These discussions in recent years urge scholars and advocates to revisit toxic stressors in early life as well as to expand the understanding of ACEs by accounting for poverty, peer victimization, and community violence [60-62]. Our study responds to these points by identifying the pattern of ACEs in kind and including other important adversities. Our study suggests four distinct groups. The three 
groups of Child Maltreatment, Household Dysfunction, and Low Adversity are consistently found in previous studies. Our findings do not identify those exposed to most types of ACEs globally, whereas some studies report such group, often labeled as high adversity or polyvictimization [62].

More importantly, our extended understanding of ACEs identifies the Violence as a distinct group, which is missed in many ACEs research. The Violence group has remarkably high exposures to physical victimization (i.e., being jumped) or a life-threatening risk (e.g., with a gun or knife). These violent experiences would include direct and indirect experiences of intimate partner / domestic violence in their households, peer victimization, and community violence. Our population-based estimate indicates that $5 \%$ of participants were classified as the Violence group. Our ACE measures do not include bullying due to data unavailability, although bullying may be a traumatic experience with lasting effects [63]. We suspect that the estimate might be higher if non-physical forms of peer victimization were able to be accounted for. Abundant empirical evidence suggests that early exposure to domestic violence is harmful, potentially resulting in victimization and perpetration of violence in later life [64]. Likewise, exposure to peer victimization and community violence are shared concerns for children and adolescents as they increase social interactions with peers in school and neighborhoods outside their home [65]. Also, our data show that racial and ethnic minorities, Blacks and Hispanics, are highly observed in the Violence group. This corresponds to the literature suggesting that over-representation of racial and ethnic minorities in violence may be attributed to limited educational and economic opportunities, racism, and structured social disadvantages [66]. Thus, ACE researchers and practitioners are highly encouraged to consider peer victimization and community violence as significant early adversities, in addition to domestic violence. Future direction should pay attention to the racial/ethnic disparities in different exposure to ACEs and associated outcomes.

This study suggests child maltreatment as a major risk for depressive symptoms and self-esteem as one plausible mediating mechanism, adjusting for socio-demographic factors and early depressive symptoms. It is striking that the negative consequence of child maltreatment stands out significantly more than other types of adversities. A significant effect of child maltreatment on depressive symptoms resembles that in self-esteem as well. Self-esteem is lower for those exposed to child maltreatment than those in other adversity groups, and consequently, the final path analysis indicates a mediation of self-esteem in the association between child maltreatment and depressive symptoms. This evidence corroborates previous research that documents child abuse and neglect as detrimental factors leading to depressive symptoms and psychiatric symptoms as well as low levels of self-esteem [67-69]. This result is consistent with previous studies indicating that child abuse is more likely to have a significant impact on adult health risks than other adversities (e.g., domestic violence, parental divorce, or incarceration) while effects of other adversities may attenuate with or get confounded by socioeconomic conditions [70]. Abuse and neglect by parents and primary caregivers are traumatic in the developmental stages of childhood and adolescence. Child maltreatment is a direct and actual incident for victims, which would provoke reactions and feelings more profoundly than other adversities. Personal exposure and recollection appear persistent and strong for maltreated children and adolescents, as researchers underscore that subjective reports of child maltreatment are more highly linked to mental health risks than objective reports and records [71].

Furthermore, this study supports that self-esteem mediates the association of child maltreatment with depressive symptoms. Our results align with prior evidence that connects childhood abuse and neglect with insecure attachment problems, a poor self-concept, low self-esteem, and poor mental health $[72,73]$. The experiences and perceptions of child maltreatment increase self-shame and lower self-esteem, which in turn results in adulthood depressive symptoms. This mechanism is concerning in that those exposed to child abuse and neglect have a high risk of interpersonal relationship problems with peers and partners and, in turn, repeat the vicious cycle of toxic environments in adulthood that feature intimate partner violence and/or violence perpetration [73, 74].

The findings for the other adversity groups should be noted. Previous studies demonstrate a general agreement that exposure to peer victimization and community violence results in psychological distress, such as depressive symptoms $[75,76]$. This relationship or strength may vary by the nature and context of violent experiences, such as victimization or witnessing an event, and also when (other) post-traumatic stress, individual characteristics, and socioeconomic environments are accounted for [77, 78]. Our study tells that exposure to violence in childhood and adolescence is accompanied by a higher risk of depressive symptoms compared to the low adversity class, yet not through self-esteem; also, a lower risk than Household Dysfunction but not significantly different. Another interesting finding is no significant difference for Household Dysfunction even compared to the Low Adversity group. This association may be explained largely by other socioeconomic conditions, or exposure to household dysfunction might be more likely to be related to other outcomes, for instance, antisocial behavior [79]. Future studies are encouraged to replicate our study to investigate the effects of co-occurring ACEs patterns on depressive symptoms and find relevant mediating mechanisms in the pathway. 


\section{Limitations}

We should acknowledge the limitations of this study. Most of all, this study employs data from multiple time points to ensure a time order and control for earlier depressive symptoms. Nevertheless, this non-experimental design may be unable to test a causal pathway. In addition, our ACE measures are not perfect. The ACE items used different time references in the data, for instance, age $18,6^{\text {th }}$ grade, or last month. The study could not include a bullying experience due to data unavailability, though it is common in various formats [80]. Our data came from mixed retrospective reports of the adolescent participants and their main caregivers. Also, recall bias or the discrepancy between different respondents in the household cannot be ruled out, although past research suggests that recall bias is not significantly concerning in ACEs [81, 82]. ACEs in our study are examined by distinct patterns. The cumulative effects might present another picture with different approaches (e.g., intensity, frequency, chronicity). We recommend future studies to address these gaps.

\section{Conclusion}

Systematic reviews suggest negative consequences associated with ACEs throughout the life course that include mental illness, chronic disease, substance use, violence, and self-destructive behaviors [9]. Our population-based estimates identify four patterns of ACEs in kind and agree with extended understandings of ACEs beyond home environments. Moreover, the findings highlight a significant effect of child maltreatment on adulthood depression, relative to other adversities, and self-esteem as one plausible mechanism. These empirical findings support the critical needs for the screening of expanded ACEs and priority setting for the most vulnerable victims in both prevention and intervention. Collaboration efforts should be coordinated across various settings, such as schools, social service agencies, health care agencies, and criminal justice agencies. Home visiting services for maternal health and primary health care can integrate regular services of identifying existing adversities and potential risks around home environments. Schools and community/social service agencies should contribute to screening ACEs risk and providing trauma-informed programs that strengthen self-esteem and resilience and help neutralize lasting effects of ACEs, in particular abuse/neglect and violence.

The types and the respective prevalence of ACEs may change to some extent over time, but the consequences remain detrimental to mental health [83]. As the current
COVID-19 pandemic continues, many families suffer from surged socioeconomic stressors, for example, unemployment, limited school opening, and social isolation, not to speak of health concerns. Family stress in the emerging context may increase ACE exposures and the negative consequences, especially in low-resource and racial/ ethnic minority communities. Concerns are growing that school closures and social distancing make it hard to detect risks of ACEs, notably child abuse and neglect [84]. Furthermore, multiple types of ACEs are likely to rise, for instance, poly-victimization of child maltreatment and violence. Researchers and practitioners should partner in estimating potential areas/groups of higher risks and continue to develop innovative strategies for the safety of children.

Acknowledgements We appreciate administrative support from Virginia Commonwealth University School of Social Work. This research uses data from Add Health, a program project directed by Kathleen Mullan Harris and designed by J. Richard Udry, Peter S. Bearman, and Kathleen Mullan Harris at the University of North Carolina at Chapel Hill, and funded by grant P01-HD31921 from the Eunice Kennedy Shriver National Institute of Child Health and Human Development, with cooperative funding from 23 other federal agencies and foundations. Information on how to obtain the Add Health data files is available on the Add Health website (http://www.cpc.unc.edu/addhealth). No direct support was received from grant P01-HD31921 for this analysis.

Funding This research did not receive any specific grant from funding agencies in the public, commercial, or not-for-profit sectors.

\section{Declarations}

Conflict of interest The authors have indicated they have no potential conflicts of interest to disclose.

\section{References}

1. Anda RF, Butchart A, Felitti VJ, Brown DW (2010) Building a framework for global surveillance of the public health implications of adverse childhood experiences. Am J Prev Med 39(1):9398. https://doi.org/10.1016/j.amepre.2010.03.015

2. Center for Disease Control and Prevention (n.d.) Adverse Childhood Experiences (ACEs). https://www.cdc.gov/violenceprevent ion/aces/index.html. Accessed 15 Jan 2021

3. Dube SR, Miller JW, Brown DW, Giles WH, Felitti VJ, Dong M, Anda RF (2006) Adverse childhood experiences and the association with ever using alcohol and initiating alcohol use during adolescence. J Adolesc Health 38:444.e1-444.e10. https://doi.org/ 10.1016/j.jadohealth.2005.06.006

4. Felitti VJ, Anda RF, Nordenberg D, Williamson DF, Spitz AM, Edwards V, Koss MP, Marks JS (1998) Relationship of childhood abuse and household dysfunction to many of the leading cause of death in adults: The Adverse Childhood Experiences (ACE) study. Am J Prev Med 14(4):245-258. https://doi.org/10.1016/ S0749-3797(98)00017-8

5. Sack V, Murphey D (2018) The prevalence of adverse childhood experiences, nationally, by state, and by race or ethnicity. Child Trends. https://www.childtrends.org/publications/preva 
lence-adverse-childhood-experiences-nationally-state-race-ethni city. Accessed 15 Jan 2021

6. Dong M, Anda RF, Felitti VJ, Dube SR, Williamson DF, Thompson TJ, Loo CM, Giles WH (2004) The interrelatedness of multiple forms of childhood abuse, neglect, and household dysfunction. Child Abuse Negl 28(7):771-784. https://doi.org/10.1016/J. CHIABU.2004.01.008

7. Mersky JP, Janczewski CE, Topitzes J (2017) Rethinking the measurement of adversity: Moving toward second-generation research on adverse childhood experiences. Child Maltreat 22(1):58-68. https://doi.org/10.1177/1077559516679513

8. Brown MJ, Thacker LR, Cohen SA (2013) Association between adverse childhood experiences and diagnosis of cancer. PLoS ONE 8(6):e65524. https://doi.org/10.1371/journal.pone.0065524

9. Hughes K, Bellis MA, Hardcastle KA, Sethi D, Butchart A, Mikton C, Jones L, Dunne MP (2017) The effect of multiple adverse childhood experiences on health: A systematic review and metaanalysis. Lancet Public Health 2:e356-e366. https://doi.org/10. 1016/S2468-2667(17)30118-4

10. Merrick MT, Ports KA, Ford DC, Afifi TO, Gershoff ET, GroganKaylor A (2017) Unpacking the impact of adverse childhood experiences on adult mental health. Child Abuse Negl 69:10-19. https://doi.org/10.1016/j.chiabu.2017.03.016

11. Lee H, Kim Y, Terry J (2020) Adverse childhood experiences (ACEs) on mental disorders in young adulthood: Latent classes and community violence exposure. Prevent Med 134. https://doi. org/10.1016/j.ypmed.2020.106039

12. Finkelhor D, Shattuck A, Turner H, Hamby S (2013) Improving the adverse childhood experiences study scale. JAMA Pediatr 167(1):70-75. https://doi.org/10.1001/jamapediatrics.2013.420

13. Merians AN, Baker MR, Frazier P, Lust K (2019) Outcomes related to adverse childhood experiences in college students: Comparing latent class analysis and cumulative risk. Child Abuse Negl 87:51-64. https://doi.org/10.1016/j.chiabu.2018.07.020

14. Roos LE, Afifi TO, Martin CG, Pietrzak RH, Tsai J, Sareen J (2016) Linking typologies of childhood adversity to adult incarceration: Findings from a nationally representative sample. Am J Orthopsychiatry 86(5):584-593. https://doi.org/10.1037/ort00 00144

15. Cronholm PF, Forke CM, Wade R, Bair-Merritt MH, Davis M, Harkins-Schwarz M, Pachter LM, Fein JA (2015) Adverse childhood experiences: Expanding the concept of adversity. Am J Prev Med 49(3):354-361. https://doi.org/10.1016/j.amepre.2015.02. 001

16. Ports KA, Ford DC, Terrick MT (2016) Adverse childhood experiences and sexal victimization in adulthood. Child Abuse Negl 51:313-322. https://doi.org/10.1016/j.chiabu.2015.08.017

17. Lee H, Larkin E (2017) Exposure to community violence as a new adverse childhood category: Promising results and future considerations. Fam Soc 98(1):69-78. https://doi.org/10.1606/ 1044-3894.2017.10

18. Lee H, Kim Y, Terry J (2020) Adverse childhood experiences(ACEs) on mental disorders in young adulthood: Latent classes and community violence exposure. Preventive Med 134:106039. https://doi.org/10.1016/j.ypmed.2020.106039

19. Wade R Jr, Cronholm PF, Fein JA, Forke CM, Davis MB, Harkins-Schwarz M, Pachter LM, Bair-Merritt MH (2016) Household and community-level adverse childhood experiences and adult health outcomes in a diverse urban population. Child Abuse Negl 52:135-145. https://doi.org/10.1016/j.chiabu.2015.11.021

20. Chapman DP, Whitfield CL, Felitti VJ, Dube SR, Edwards VJ, Anda RF (2004) Adverse childhood experiences and the risk of depressive disorders in adulthood. J Affect Disord 82(2):217-225. https://doi.org/10.1016/j.jad.2003.12.013

21. Jewkes RK, Dunkle K, Nduna M, Jama PN, Puren A (2010) Associations between childhood adversity and depression, substance abuse and HIV and HSV2 incident infections in rural South African youth. Child Abuse Negl 34(11):833-841. https://doi.org/10. 1016/j.chiabu.2010.05.002

22. Manyema M, Norris SA, Richter LM (2018) Stress begets stress: The association of adverse childhood experiences with psychological distress in the presence of adult life stress. BMC Public Health 18:835. https://doi.org/10.1186/s12889-018-5767-0

23. Sareen J, Henriksen CA, Bolton SL, Afifi TO, Stein MB, Asmundson GJG (2013) Adverse childhood experiences in relation to mood and anxiety disorders in a population-based sample of active military personnel. Psychol Med 43(1):73-84. https://doi.org/10. 1017/S003329171200102X

24. LaNoue M, Graeber D, de Hernandez BU, Warner TD, Helitzer DH (2012) Direct and indirect effects of childhood adversity on adult depression. Community Ment Health J 48:187-192. https:// doi.org/10.1007/s10597-010-9369-2

25. Anda RF, Felitti VJ, Bremner JD, Walker JD, Whitfield C, Perry BD, Dube SR, Giles WH (2006) The enduring effects of abuse and related adverse experiences in childhood: A convergence of evidence from neurobiology and epidemiology. Eur Arch Psychiatry Clin Neurosci 256(3):174-186. https://doi.org/10.1111/j. 1365-2214.2006.00614_2.x

26. Almuneef M, Hollinshead D, Saleheen H, AlMadani S, Derkash B, AlBuharian F, Al-Elissa M, Fluke J (2016) Adverse childhood experiences and association with health, mental health, and risky behavior in the kingdom of Saudi Arabia. Child Abuse Negl 60:10-17. https://doi.org/10.1016/j.chiabu.2016.09.003

27. Remigio-Baker RA, Hayes DK, Reyes-Salvail F (2014) Adverse childhood events and current depressive symptoms among women in Hawaii: 2010 BRFSS. Hawaii Matern Child Health J 18:2300 2308. https://doi.org/10.1007/s10995-013-1374-y

28. Zimmer-Gemeck MJ, Skinner EA (2016) The development of coping: Implications for psychopathology and resilience. In: Cicchetti D (ed) Developmental psychopathology: Risk, resilience, and intervention. John Wiley \& Sons Inc, Hoboken, pp 485-545

29. Liu RT, Kleiman EM, Nestor BA (2015) The hopelessness theory of depression: A quarter century in review. Clin Psychol 22(4):345-365. https://doi.org/10.1111/cpsp.12125

30. Bowlby J (1982) Attachment and loss: Attachment. Basic Books, New York

31. Harter S (1998) The effects of child abuse on the self-system. J Aggress Maltreatment Trauma 2:147-169. https://doi.org/10. 1300/J146v02n01_09

32. Huang DYC, Lanza HI, Wright-Volel K, Anglin MD (2013) Developmental trajectories of childhood obesity and risk behaviors in adolescence. J Adolesc 36(1):139-148. https://doi.org/10. 1016/j.adolescence.2012.10.005

33. Ternouth A, Collier D, Maughan B (2009) Childhood emotional problems and self-perceptions predict weight gain in a longitudinal regression model. BMC Med 7(1):46. https://doi.org/10.1186/ 1741-7015-7-46

34. Sowislo JF, Orth U (2013) Does low self-esteem predict depression and anxiety? A meta-analysis of longitudinal studies. Psychol Bull 139(1):213-240. https://doi.org/10.1037/a0028931

35. Cole PM, Luby J, Sullivan MW (2008) Emotions and the development of childhood depression: Bridging the gap. Child Dev Perspect 2:141-148. https://doi.org/10.1111/j.1750-8606.2008. 00056.x

36. Hymowitz G, Salwen J, Salis KL (2017) A meditational model of obesity related disordered eating: The roles of childhood emotional abuse and self-perception. Eat Behav 26:27-32. https://doi. org/10.1016/j.eatbeh.2016.12.010

37. Shen AC-T (2009) Self-esteem of young adults experiencing interparental violence and child physical maltreatment: Parental and peer relationships as mediators. J Interpers Violence 24(5):770 794. https://doi.org/10.1177/0886260508317188 
38. Chartier MJ, Walker JR, Naimark B (2009) Health risk behaviors and mental health problems as mediators of the relationship between childhood abuse and adult health. Am J Public Health 99(5):847-954. https://doi.org/10.2105/AJPH.2007.122408

39. Kim J, Cicchetti D (2006) Longitudinal trajectories of self-system processes and depressive symptoms among maltreated and nonmaltreated children. Child Dev 77(3):624-639. https://doi.org/10. 1111/j.1467-8624.2006.00894.x

40. Ho GWK, Bressington D, Karatzias T, Chien WT, Inoue S, Yang PJ, Hyland P, Chan ACY (2020) Patterns of exposure to adverse childhood experiences and their associations with mental health: a survey of 1346 university students in East Asia. Soc Psychiatry Psychiatr Epidemiol 55(3):339-349. https://doi.org/10.1007/ s00127-019-01768-w

41. Holt MK, Felix E, Grimm R, Nylund-Gibson K, Green JG, Poteat VP, Zhang C (2017) A latent class analysis of past victimization exposures as predictors of college mental health. Psychol Violence 7(4):521-532. https://doi.org/10.1037/vio0000068

42. Kim Y, Kim K, Chartier K, Wike T, McDonald S (2019) Adverse childhood experience patterns, major depressive disorder, and substance use disorder in older adults. Aging Ment Health. https:// doi.org/10.1080/13607863.2019.169397

43. Chen P, Chantala K (2014) Guidelines for analyzing Add Health data. Carolina Population Center Univ NC, Chapel Hill

44. Harris KM (2013) The Add Health Study: Design and accomplishments. https://addhealth.cpc.unc.edu/wp-content/uploads/ docs/user_guides/DesignPaperWave_I-IV.pdf. Accessed 15 Jan 2021

45. Zhang W, O'Brien N, Forrest JI, Salters KA, Patterson TL, Montaner JS, Lima VD (2012) Validating a shortened depression scale (10 item CES-D) among HIV-positive people in British Columbia. Canada PloS One 7(7):e40793. https://doi.org/10.1371/journal. pone. 0040793

46. Brumley LD, Jafee SR, Brumley BP (2017) Pathways from childhood adversity to problem behaviors in young adulthood: The mediating role of adolescents' future expectations. J Youth Adolesc 46:1-14. https://doi.org/10.1007/s10964-016-0597-9

47. Doom JR, Mason SM, Suglia SF, Clark CJ (2017) Pathways between childhood/adolescent socioeconomic status, and longterm cardiovascular disease risk in young adulthood. Soc Sci Med 188:166-175. https://doi.org/10.1016/j.socscimed.2017.06.044

48. London S, Quinn K, Scheidell JD, Frueh BC, Khan MR (2017) Adverse experiences in childhood and sexually transmitted infection risk from adolescence into adulthood. Sex Transm Dis 44(9):524-532. https://doi.org/10.1097/OLQ.0000000000000640

49. Bulloch A, Williams J, Lavorato DH, Patten SB (2017) The depression and marital status relationship is modified by both age and gender. J Affect Disord 223(1):65-68. https://doi.org/10. 1016/j.jad.2017.06.007

50. Casey P, Goolsby S, Berkowitz C, Frank D, Children's Sentinel Nutritional Assessment Program Study Group (2004) Mental depression, changing public assistance, food security, and child health status. Pediatrics 113(2):298-304. https://doi.org/10.1542/ peds.113.2.298

51. Gotlib IH, Lewinsohn PM, Seeley JR (1998) Consequences of depression during adolescence: marital status and marital functioning in early adulthood. J Abnorm Psychol 107(4):686-690. https://doi.org/10.1037//0021-843x.107.4.686

52. Thapar A, Collishaw S, Pine DS, Thapar AK (2012) Depression in adolescence. The Lancet 379(9820):1056-1067. https://doi.org/ 10.1016/S0140-6736(11)60871-4

53. Zlotnick C, Miller IW, Pearlstein T (2006) A preventive intervention for pregnant women on public assistance at risk for postpartum depression. Am J Psychiatry 163(8):1443-1445. https://doi. org/10.1176/ajp.2006.163.8.1443
54. Nylund-Gibson K, Choi AY (2018) Ten frequently asked questions about latent class analysis. Transl Issue Psychologi Sci 4(4):440-461. https://doi.org/10.1037/tps0000176

55. Magidson J, Vermunt JK (2004) Latent class models. In: Kaplan D (ed) The SAGE handbook of quantitative methodology for the social sciences. SAGE Publications Inc, New York City, pp $175-198$

56. Nagin DS (2005) Group-based modeling of development. Harvard University Press, Cambridge, MA

57. Asparouhov T, Muthen B (2021) Auxiliary variables in mixture modeling: Using the $\mathrm{BCH}$ method in Mplus to estimate a distal outcome model and an arbitrary second model (Mplus Web Notes: No. 21, Version 11). Retrieved from https://www.statmodel.com/ examples/webnotes/webnote21.pdf

58. Bolck A, Croon M, Hagenaars J (2004) Estimating latent structure models with categorical variables: One-step versus threestep estimators. Polit Anal 12(1):3-27. https://doi.org/10.1093/ $\mathrm{pan} / \mathrm{mph} 001$

59. Nylund-Gibson K, Grimm RP, Masyn KE (2019) Prediction from latent classes: A demonstration of different approaches to include distal outcomes in mixture models. Struct Equ Modeling 26(6):967-985. https://doi.org/10.1080/10705511.2019.1590146

60. Afifi TO, Salmon S, Garcés I, Struck S, Fortier J, Taillieu T, Stewart-Tufescu A, Asmundson G, Sareen J, MacMillan HL (2020) Confirmatory factor analysis of adverse childhood experiences (ACEs) among a community-based sample of parents and adolescents. BMC Pediatr 20:1-14. https://doi.org/10.1186/ s12887-020-02063-3

61. Finkelhor D, Shattuck A, Turner H, Hamby S (2015) A revised inventory of adverse childhood experiences. Child Abuse Negl 48:13-21. https://doi.org/10.1016/j.chiabu.2015.07.011

62. McLennan JD, MacMillan HL, Afifi TO (2020) Questioning the use of adverse childhood experiences (ACEs) questionnaires. Child Abuse Negl 101:104331. https://doi.org/10.1016/j.chiabu. 2019.104331

63. Kennedy RS (2019) Bullying trends in the United States: A metaregression. Trauma Violence Abuse. https://doi.org/10.1177/ 1524838019888555

64. Roberts AL, Gilman SE, Fitzmaurice G, Decker MR, Koenen KC (2010) Witness of intimate partner violence in childhood and perpetration of intimate partner violence in adulthood. Epidemiol 21(6):809. https://doi.org/10.1097/EDE.0b013e3181f39f03

65. Salmon S, Turner S, Taillieu T, Fortier J, Afifi TO (2018) Bullying victimization experiences among middle and high school adolescents: Traditional bullying, discriminatory harassment, and cybervictimization. J Adolesc 63:29-40. https://doi.org/10.1016/j. adolescence.2017.12.005

66. Wilson WJ (2012) The truly disadvantaged: The inner city, the underclass, and public policy, 2nd edn. University of Chicago Press, Chicago

67. Frederico MM, Jackson AL, Black CM (2008) Understanding the impact of abuse and neglect on children and young people referred to a therapeutic program. J Fam Stud 14(2-3):342-362. https:// doi.org/10.5172/jfs.327.14.2-3.342

68. Gilbert R, Widom CS, Browne K, Fergusson D, Webb E, Janson S (2009) Burden and consequences of child maltreatment in high-income countries. Lancet 373(9657):68-81. https://doi.org/ 10.1016/S0140-6736(08)61706-7

69. Harkness KL, Lumley MN (2008) In: Abela JRZ, Hankin BL (eds) Child abuse and neglect and the development of depression in children and adolescents. Guilford Press, New York

70. Font SA, Maguire-Jack K (2016) Pathways from childhood abuse and other adversities adult health risks: The role of adult socioeconomic conditions. Child Abuse Negl 51:390-399. https://doi. org/10.1016/j.chiabu.2015.05.013 
71. Danese A, Widom CP (2020) Objective and subjective experiences of child maltreatment and their relationships with psychopathology. Nat Hum Behav 4:1-8. https://doi.org/10.1038/ s41562-020-0880-3

72. Baer JC, Martinez CD (2006) Child maltreatment and insecure attachment: A meta-analysis. J Reprod Infant Psychol 24(3):187197. https://doi.org/10.1080/02646830600821231

73. Meadows P, Tunstill J, George A, Dhudwar A, Kurtz Z (2011) The costs and consequences of child maltreatment. National Institute of Economic and Social Research, London

74. Trickett PK, Negriff S, Ji J, Peckins M (2011) Child maltreatment and adolescent development. J Res Adolesc 2(1):3-20. https://doi. org/10.1111/j.1532-7795.2010.00711.x

75. Bogart LM, Elliot MN, Klein DJ, Tortolero SR, Mrug S, Peskin MF, Davies SL, Schink ET, Schuster MA (2014) Peer victimization in fifth grade and health in tenth grade. Pediatrics 133(3):440-447. https://doi.org/10.1542/peds.2013-3510

76. Earshaw VA, Elliott MN, Reisner SL, Mrug S, Windle M, Emery ST, Peskin MF, Schuster MA (2017) Peer victimization, depressive symptoms and substance abuse: A longitudinal analysis. Pediatrics 139(6):e20163426. https://doi.org/10.1542/peds.2016-3426

77. McDonald CC, Richmond TR (2008) The relationship between community violence exposure and mental health symptoms in urban adolescents. J Psychiatr Ment Health Nurs 15(10):833-849. https://doi.org/10.1111/j.1365-2850.2008.01321.x

78. Lopez V, Benbenishty R, Astor RA, Ascorra P, Gonzalez L (2018) Teachers victimizing students: Contributions of student-to-teacher victimization, peer victimization, school safety, and school climate in Chile. Am J Orthopsychiatry 90(4):432-444. https://doi.org/10. 1037/ort0000445

79. Murray J, Farrington DP, Sekol I (2012) Children's antisocial behavior, mental health, drug use, and educational performance after parental incarceration: A systematic review and meta-analysis. Psychol Bull 138(2):175-210. https://doi.org/10.1037/a0026 407

80. Elgar FJ, McKinnon B, Walsh SD, Freeman J, Donnelly PD, de Matos MG, Gariepy G, Aleman-Diaz AY, Pickett W, Molcho M, Currie C (2015) Structural determinants of youth bullying and fighting in 79 countries. J Adolesc Health 57(6):643-650. https:// doi.org/10.1016/j.jadohealth.2015.08.007

81. Hardt J, Rutter M (2004) Validity of adult retrospective reports of adverse childhood experiences: review of the evidence. J Child Psychol Psychiatry 45(2):260-273. https://doi.org/10.1111/j. 1469-7610.2004.00218.x

82. Teicher MH, Samson JA (2016) Annual research review: enduring neurobiological effects of childhood abuse and neglect. J Child Psychol Psychiatry 57(3):241-266. https://doi.org/10.1111/jcpp. 12507

83. Finkelhor D (2020) Trends in adverse childhood experiences (ACEs) in the United States. Child Abuse Negl 108:104641. https://doi.org/10.1016/j.chiabu.2020.104641

84. Campbell AM (2020) An increasing risk of family violence during the Covid-19 pandemic: Strengthening community collaborations to save lives. Forensic Sci Int Rep 2:100089. https://doi.org/10. 1016/j.fsir.2020.100089 